\title{
A PROFILE OF BLOOD PRESSURE PATTERN IN SCHOOL GOING CHILDREN AGED 6 TO 12 YEARS IN SUBURBAN CHENNAI
}

Suresh $\mathrm{P}^{1}$, Antony $\mathrm{J}^{2}$, Ambujavalli B. T33 , Thirunavukarasu $\mathrm{H}^{4}$

\section{HOW TO CITE THIS ARTICLE:}

Suresh P, Antony J, Ambujavalli B. T, Thirunavukarasu H. "A Profile of Blood Pressure Pattern in School Going Children Aged 6 To 12 Years in Suburban Chennai". Journal of Evolution of Medical and Dental Sciences 2014; Vol. 3, Issue 30, July 28; Page: 8387-8392, DOI: 10.14260/jemds/2014/3057

ABSTRACT: AIM: To study Blood Pressure (B.P.) Pattern in normal school children in the age group of 6-12 years. OBJECTIVES: To determine Blood pressure pattern in school going children so that the prevalence of Hypertension in young adults can be predicted and mortality due to the disease can be prevented. MATERIALS AND METHODS: It is a Prospective cross sectional study with Sample Size 1,400 children (Minimum 100 in each group). Children of both sexes between the age group of $6-12$ years were selected were included. Children with Renal diseases and Family history of hypertension were excluded. Study Period: 1 Year (from January 2013 to December 2013). RESULTS: The results were analyzed with suitable statistical package with student ' $t$ ' test, paired ' $t$ ' test. Analysis of variance (ANOVA), Chi square tests. CONCLUSION: There is presently a lack of longitudinal data relating BP measurement in childhood to the risk of further cardiovascular disease. it would be logical to advice families with obese children to change their lifestyles with respect to diet, exercise and reduced salt intake to get their children accustomed to lifestyles which are favorable for the maintains of normal blood pressure.

KEYWORDS: Blood pressure, School going children.

INTRODUCTION: Blood pressure is an important physical sign as the body temperature, pulse rate and respiratory rate in childhood. But recording of blood pressure is often neglected in pediatric practice.

Recent emphasis on hypertension ${ }^{1}$ and its possible origin during childhood has served as an impetus for pediatrician. In the hospitalized patient, it is considered as an important and routine test like documentation of body temperature, pulse rate and respiratory rate. In the office, it is now common practice to measure and record the blood pressure in all the children including new born. Primary prevention of one of the leading health problems like hypertension and ischemic heart disease in adults necessitates a scientific evaluation of the predictors in children. Blood pressure studies in children provide important epidemiological information which may help in controlling or modifying the risk factors.

The underlying process of growth and maturation is closely linked to the blood pressure in children. India ${ }^{1}$ is a vast country with divergent customs, dietary habits and socio-economic background. The data on blood pressure profile in Indian children is inadequate with few studies showing different patterns of normal blood pressure.

AIM: To study Blood Pressure (B.P.) Pattern in normal school children in the age group of $6-12$ years. 
OBJECTIVES: To determine Blood pressure pattern inschool going children so that the prevalence of Hypertension in young adults can be predicted and mortality due to the disease can be prevented.

MATERIALS AND METHODS: It is a Prospective cross sectional study with Sample Size 1,400 children (Minimum 100 in each group). Children of both sexes between the age group of 6-12 years were selected were included. Children with Renal diseases and Family history of hypertension were excluded. Study Period: 1 Year (from January 2013 to December 2013). Before taking the BP the children were familiarized with the procedure and the efforts made to eliminate the factors which affect BP such as Anxiety, Fear, Stress, Crying, Laughing, recent activity abnormalbody temperature etc. Every child in the class was given a precoded proforma which he/ she was advised to bring the next day after getting it filled by his/her parents. This proforma was designed to obtain information with reference to history of Hypertension, Renal Diseases and any drug intakein the parents and children and socioeconomic status.

The following day 25 children at a time are called to the room where physical examination to be performed. The age of the child was recorded in complete years and verified with their birth records. Every effort including interview with the teacher's evaluation of the school records as well as inspection of other documents if any were used for confirmation of the exact age of the child. Height and weight was measured in every child using standard techniques.Random checking of height and weight measurements was cross checked by another examiner. Auscultatory method was used to measure blood pressure with a standard mercury sphygmomanometer. Same blood pressure instrument was used throughout the study and was standardized periodically.

RESULTS: The study sample consists of 1400 with each of 100 in each group of Boys and Girls. The results were analyzed with suitable statistical package with student' $t$ ' test, paired ' $t$ ' test. Analysis of variance (ANOVA), Chi square tests. The following arethe observations such as:

1. Normogram of B.P.

2. B.P. in relations to age and sex.

The statistically significant are as follows:

1. The SBP in 6 year old boys being greater than the girls $P$ value $<0.05$

2. The SBP in 9 year old girls being greater than the boys. $P$ value $<0.01$

3. SBP of 10 year old girls being greater than boys. P value $<0.001$.

4. SBP of 11 year old girls being greater than the boys $P$ value $<0.001$.

5. The DBP of 12 year old boys being greater than girls. P value $<0.001$.

The other statistically non-significant results are: In 8 years group, the SBP of girls is greater than that of boys; DBP of boys is greater than that of the girls. In these two age groups BP is increased in severely malnourished compared to normal BP, contrary to other age groups. The percentage distribution of BP in boys and girls in different age groups is presented in Table 2.

Hence as per this study, SBP \& DBP of 6 and 7 year old boys and girls are almost the same. 


\begin{tabular}{|c|c|c|c|c|c|c|c|c|c|c|c|c|c|c|c|c|}
\hline \multirow{3}{*}{ Age } & \multicolumn{4}{|c|}{ V.K.Agarwal } & \multicolumn{4}{|c|}{ Sol.Londe M.D. } & \multicolumn{4}{|c|}{ N.K. Anand\&LalitTandon } & \multicolumn{4}{|c|}{ D.Laroia } \\
\hline & \multicolumn{2}{|c|}{ Male } & \multicolumn{2}{|c|}{ Female } & \multicolumn{2}{|c|}{ Male } & \multicolumn{2}{|c|}{ Female } & \multicolumn{2}{|c|}{ Male } & \multicolumn{2}{|c|}{ Female } & \multicolumn{2}{|c|}{ Male } & \multicolumn{2}{|c|}{ Female } \\
\hline & SP & $\mathrm{DP}$ & SP & DP & SP & DP & SP & DP & SP & $\mathrm{DP}$ & SP & DP & SP & DP & SP & DP \\
\hline 6 & 106.65 & 70.92 & 107.79 & 70.04 & 105 & 60 & 105 & 64 & 96.3 & 64.4 & 95.0 & 64.3 & 106.85 & 70.22 & 106.06 & 70.19 \\
\hline 7 & 108.25 & 69.39 & 107.91 & 71.94 & 106 & 63 & 107 & 63 & 98.5 & 66.5 & 98.4 & 65.2 & 107.71 & 69.73 & 107.13 & 70.55 \\
\hline 8 & 108.35 & 70.51 & 110.39 & 72.52 & 108 & 61 & 108 & 65 & 100.4 & 68.0 & 100.4 & 68.1 & 108.3 & 70.45 & 107.22 & 71.10 \\
\hline 9 & 108.17 & 72.16 & 109.20 & 72.89 & 111 & 65 & 112 & 67 & 101.5 & $69 . .1$ & 101.0 & 68.3 & 108.6 & 70.87 & 108.51 & 72.06 \\
\hline 10 & 107.38 & 71.92 & 109.97 & 75.14 & 114 & 66 & 114 & 64 & 103.2 & 75.0 & 102.6 & 70.2 & 107.74 & 70.95 & 108.34 & 73.27 \\
\hline 11 & 107.53 & 70.74 & 109.16 & 72.48 & 114 & 65 & 121 & 69 & 106.3 & 72.2 & 105.7 & 72.1 & 108.89 & 70.07 & 108.59 & 71.01 \\
\hline 12 & 110.49 & 70.74 & 110.68 & 75.74 & 116 & 67 & 117 & 65 & 110.7 & 73.3 & 110.1 & 73.0 & 111.90 & 70.41 & 110.20 & 75.50 \\
\hline
\end{tabular}

\section{TABLE 1: Mean systolic and diastolic blood pressure according to age, sex from various studies}

\begin{tabular}{|c|c|c|c|c|c|}
\hline \multirow{2}{*}{ Age } & \multirow{2}{*}{ Percentiles } & \multicolumn{2}{|c|}{ Boys } & \multicolumn{2}{|c|}{ Girls } \\
\hline & & SBP & DBP & SBP & DBP \\
\hline \multirow{7}{*}{6 Yrs } & 5 & 100.00 & 62.00 & 100.00 & 62.00 \\
\hline & 10 & 100.20 & 64.00 & 106.00 & 64.00 \\
\hline & 25 & 106.00 & 66.00 & 108.00 & 66.00 \\
\hline & 50 & 110.00 & 70.00 & 110.00 & 70.00 \\
\hline & 75 & 120.00 & 72.00 & 111.50 & 72.00 \\
\hline & 90 & 120.00 & 80.00 & 117.80 & 74.00 \\
\hline & 95 & 124.00 & 81.90 & 120.00 & 80.00 \\
\hline \multirow{7}{*}{7 Yrs } & 5 & 100.00 & 62.00 & 102.00 & 64.00 \\
\hline & 10 & 104.00 & 64.00 & 106.00 & 66.00 \\
\hline & 25 & 108.00 & 66.00 & 108.00 & 68.00 \\
\hline & 50 & 110.00 & 70.00 & 110.00 & 70.00 \\
\hline & 75 & 114.00 & 70.00 & 118.00 & 72.00 \\
\hline & 90 & 120.00 & 79.60 & 120.00 & 80.00 \\
\hline & 95 & 120.00 & 80.00 & 121.90 & 80.00 \\
\hline \multirow{7}{*}{8 Yrs } & 5 & 94.00 & 58.10 & 100.00 & 60.10 \\
\hline & 10 & 96.00 & 60.00 & 100.00 & 64.00 \\
\hline & 25 & 106.00 & 64.00 & 106.00 & 66.00 \\
\hline & 50 & 110.00 & 70.00 & 110.00 & 70.00 \\
\hline & 75 & 110.00 & 70.00 & 112.00 & 70.00 \\
\hline & 90 & 119.60 & 78.00 & 120.00 & 80.00 \\
\hline & 95 & 120.00 & 80.00 & 120.00 & 80.00 \\
\hline \multirow{7}{*}{9 Yrs } & 5 & 90.10 & 60.00 & 100.00 & 60.00 \\
\hline & 10 & 96.00 & 60.00 & 102.00 & 64.00 \\
\hline & 25 & 104.50 & 64.00 & 108.00 & 70.00 \\
\hline & 50 & 110.00 & 70.00 & 110.00 & 70.00 \\
\hline & 75 & 112.00 & 72.00 & 114.00 & 72.00 \\
\hline & 90 & 120.00 & 80.00 & 120.00 & 80.00 \\
\hline & 95 & 120.00 & 80.00 & 121.90 & 80.00 \\
\hline
\end{tabular}

TABLE 2: PERCENTAGE DISTRIBUTION OF BP IN BOYS AND GIRLS 


\begin{tabular}{|c|c|c|c|c|c|}
\hline \multirow{2}{*}{ Age } & \multirow{2}{*}{ Percentiles } & \multicolumn{2}{|c|}{ Boys } & \multicolumn{2}{c|}{ Girls } \\
\cline { 2 - 6 } & SBP & DBP & SBP & DBP \\
\hline \multirow{5}{*}{10 Yrs } & 5 & 94.30 & 50.20 & 100.00 & 60.00 \\
& 10 & 100.00 & 60.00 & 106.00 & 60.00 \\
& 25 & 104.50 & 64.50 & 108.00 & 66.00 \\
& 75 & 110.00 & 70.00 & 110.00 & 70.00 \\
& 90 & 110.00 & 72.00 & 117.50 & 72.00 \\
& 95 & 119.80 & 80.00 & 120.00 & 80.00 \\
& 5 & 90.00 & 54.20 & 100.00 & 60.00 \\
& 10 & 96.00 & 60.00 & 106.00 & 64.00 \\
& 25 & 100.00 & 64.00 & 108.00 & 68.00 \\
& 50 & 108.00 & 70.00 & 110.00 & 70.00 \\
& 75 & 110.00 & 71.50 & 110.00 & 70.00 \\
& 90 & 120.00 & 80.00 & 117.60 & 72.00 \\
& 95 & 120.00 & 80.00 & 123.90 & 79.80 \\
\hline \multirow{4}{*}{ Yrs Yrs } & 5 & 108.00 & 68.00 & 100.00 & 60.00 \\
& 10 & 110.00 & 70.00 & 100.00 & 60.00 \\
& 25 & 110.00 & 70.00 & 106.50 & 66.50 \\
& 50 & 112.00 & 72.00 & 110.00 & 70.00 \\
& 75 & 120.00 & 80.00 & 120.00 & 72.00 \\
& 90 & 120.00 & 80.00 & 125.80 & 80.00 \\
& 95 & 121.90 & 82.00 & 130.00 & 81.90 \\
\hline \multirow{7}{*}{ TABLE: 2 (CONT) PERCENTAGE DISTRIBUTION OF BP IN BOYS AND GIRLS }
\end{tabular}

DISCUSSION: Obesity is increasing world-wide because developing countries are adapting Western high fat foods and sedentary lifestyles. The Association of Hypertension and obesity in adults is well recognized, but this relationship has been studied less extensively in children.

The mean systolic pressure at the age of 6 years for boys in this study is $111.52 \mathrm{mmHg}$ and that of western standard is $105 \mathrm{~mm} \mathrm{Hg}$ which was also found by some Indian authors ${ }^{2}$.

This upward trend with age correlates with the studies by other authors. The mean systolic and diastolic blood pressure was higher for all ages when compared to other studies.3,4 This study shows that the mean Blood pressure of both systolic and diastolic shows an upward trend with increase in age 5 .

The findings of present study revealed that a spurt of about $8 \mathrm{mmHg}$ in systolic Blood pressure and no spurt in diastolic blood pressure is observed from $6-7$ years in boys and a spurt of about $2 \mathrm{~mm} \mathrm{Hg}$ in SBP and 2mm Hg in DBP is observed from $6-7$ years in girls. And spurt of about 0.45 (mean) of BMI is observed in both boys and girls.

A spurt of $2 \mathrm{~mm} \mathrm{Hg}$ is observed for DBP and SBP for boys and girls between 8 and 9 years and BMI also increases by 0.50 (mean) similar observations have been made by other investigators who found a spurt of SBP, between 13-15 years age group. The task forcecommittee report found this spurt between 5-6 years in both the sexes. The spurt may possibly be due to certain hormonal and physical changes occurring in the body. 
The mean diastolic BP for boys rises from $69.90 \mathrm{mmHg}$ at the age of 6 years to $73.70 \mathrm{mmHg}$ at 12 years of age.The mean diastolic blood pressure for girls rises from $69.06 \mathrm{mmHg}$ at 6 years of age to $69.98 \mathrm{mmHg}$ at 12 years of age.

Hahn ${ }^{6}$ studying boys from 11 through 15 years of age, reported significant correlation of blood pressure with weight and height in each year.

This is in correlation with the observation of Y. Sachdev ${ }^{7}$ in which the mean DBP was 62. But when compared to the study of diastolic BP at 12 years of age by Agarwal. $\mathrm{R}^{8}$ our readings are little lower.

The average increment of SBP and DBP from 6 years to 12 years is 3-4 mm Hg. This is in correlation with Agarwal $\mathrm{R}^{8}$ and others. The mean systolic and diastolic blood pressure were higher for all ages when compared to other studies. ${ }^{8}$

Londe $S^{9}$ noted significant difference between the two sexes, $10 \mathrm{mmHg}$ higher in boys at the age of 15 years and DBP of 2-3mm and BMI of 1.5-2.0 noted in girls with age group of 10-12 years.

Haggerty ${ }^{10}$ did not observe any significant variation between two sexes both for systolic and diastolic blood pressure which is similar to our study.

Yadevet al11 in a school based study among 9-12 years old reported a prevalence of obesity as $5.6 \%$. In two other schools based studies among 8-16 years old children done in India by Desai et al ${ }^{12}$ and Gupta et al ${ }^{13} 10 \%$ were found obese.

We found that both systolic and diastolic blood pressure increased with increase of weight. Similar findings were observed by Feber et al. ${ }^{14}$

Pela et $\mathrm{al}^{15}$ reported that the alterations on B.P. of the obese children were detected by ambulatory. 24 hour monitoring and that higher SBP levels were observed 6 to 11 year old obese children both during the day and the night.

Figuer OA et $\mathrm{al}^{16}$ also reported that higher SBPs and DBPs were found with the usual B.P. check in a study of 5 to 11 year old obsese children.

CONCLUSION AND RECOMMENDATIONS: The relationship of high BP to serious medical problems has been established by measuring BP in an adult population, and following the same individuals until the consequences are observed to occur.

There is presently a lack of longitudinal data relating BP measurement in childhood to the risk of further cardiovascular disease; until this information is obtained the significance of casual elevation of BP in childhood will remain in doubt.

The long term followup of the children with BP levels in upper percentiles is mandatory and may throw some light on the natural history of essential hypertension.

Hence, it would be logical to advice families with obese children to change their lifestyles with respect to diet, exercise and reduced salt intake to get their children accustomed to lifestyles which are favorable for the maintains of normal blood pressure.

\section{BIBLIOGRAPHY:}

1. Verma M, Chhatwaz J, George, SKM. Biological profile of B.P. in school children. Indian paediatrics, 1995; 32: 749-753.

2. Agarwal VK, Sharan R, Srivatsava AK, Kumar P, Pandey CM. Blood pressure profile in children of age 3-11 years. Indian paediatrics, 1983, 20: 921-925. 
3. Laroia D, Sharma M, Diwedi V, Belapurkar KM, Mathur PS. Profile of blood pressure in normal school children. Indian paeditrics, 1989, 26: 531-536.

4. Rames et al. Normal Blood pressure and evaluation of sustained blood pressure elevation in childhood. The muscatine study. Paediatrics 1978, 61: 245 - 247.

5. Gupta AK. Influence of family history of morbid cardiovascular events on blood pressure levels of school children Indian Paediatrics. 1991, 28: 131-139.

6. Hahn. Relationship of blood pressure to weight, height, body surface area in school boys aged 11-15 years. Arch Dis Child 27; 43, 1952.

7. Sachdev Y. Normal blood pressure and hypertension. Indian Paediatrics 1984, 21: 41-49.

8. Aggarwal R. Prevalence of hypertension in apparently healthy school children. Indian Paediatrics, 1982, 19: 779-784.

9. Sol Londe MD. Blood pressure standard for children determined under office condition. Clinical Paediatrics 1968, 7: 400-403.

10. Haggerty RJ, Maroney MW, Nadas AS, Essential hypertension in infancy and childhood. Differential diagnosis and therapy. Amer. J. Dis Child 1956, 92: 535-549.

11. Yadav. S. Obesity an increasing problem in the developing countries. IJPP 4(4) 293-299. 2001.

12. Desai MP: Obesity in current management protocols in pediatric practice. Ed. S. Kukreja 1st edn. CBS. Publishers, Delhi 260 - 265, 1995.

13. Gupta AK, Ahmad AJ. Childhood obesity and hypertension. Indian Pediatrics 1990; 27: 333-337.

14. Feber HK, James CA. Blood pressure in normal children, clinical application of statistical methods to the interpretation of deviation from the normal average Am. J. Dis child 1921; 22: 7 $-28$.

15. Pela I, Modesti PA, Cocchic, Cecioni I, Gensini GF, Bartolozzi G. Changes in the ambulatory Arterial Pressure of Normotensive obese children. Pediatric Med. Chir. 1990; 12: 495-497.

16. Figueroa CR, Franklin FA, Lee JY, Aldridge R, Alexander L. Prevalence of obesity with increased blood pressure in elementary school aged childrens. South Med. J. 1997; 90-806-813.

\section{AUTHORS:}

1. Suresh P.

2. Antony J.

3. Ambujavalli B. T.

4. Thirunavukarasu $\mathrm{H}$.

\section{PARTICULARS OF CONTRIBUTORS:}

1. Associate Professor, Department of Paediatrics, Chettinad Hospital and Research Institute, Chennai.

2. Assistant Professor, Department of Paediatrics, Chettinad Hospital and Research Institute, Chennai.

3. Senior Resident, Department of Microbiology, Sri Ramachandra University, Chennai.
4. Professor, Department of Paediatrics, Sri Ramachandra University,Chennai.

\section{NAME ADDRESS EMAIL ID OF THE CORRESPONDING AUTHOR:}

Dr. P. Suresh, Old No. 4, New No. 8/1, Balu Avenue, Valmiki Street, Thiruvanmiyur, Chennai-41

Email: sureshp39@ymail.com

Date of Submission: 01/07/2014. Date of Peer Review: 02/07/2014. Date of Acceptance: 07/07/2014. Date of Publishing: 23/07/2014. 